\title{
The ethical dimensions of space settlement
}

\author{
Martyn J. Fogg \\ Probability Research Group, c/o 44 Hogarth Court, Fountain Drive, London, SE19 IUY, UK
}

\begin{abstract}
While proposals for settling in the space frontier have appeared in the technical literature for over 20 years, it is in the case of Mars that the ethical dimensions of space settlement have been most studied. Mars raises the questions of the rights and wrongs of the enterprise more forcefully because: (a) Mars may possess a primitive biota; and (b) it may be possible to terraform Mars and transform the entire planet into a living world. The moral questions implicit in space settlement are examined below from the standpoints of four theories of environmental ethics: anthropocentrism, zoocentrism, ecocentrism and preservationism. In the absence of extraterrestrial life, only preservationism concludes that space settlement would be immoral if it was seen to be to the benefit of terrestrial life. Even if Mars is not sterile, protection for Martian life can be argued for either on intrinsic or instrumental grounds from the standpoints of all of these theories. It is argued further that a strict preservationist ethic is untenable as it assumes that human consciousness, creativity, culture and technology stand outside nature, rather than having been a product of natural selection. If Homo sapiens is the first spacefaring species to have evolved on Earth, space settlement would not involve acting 'outside nature', but legitimately 'within our nature'. (C) 1999 International Astronautical Federation or the International Academy of Astronautics. Published by Elsevier Science Ltd. All rights reserved.
\end{abstract}

\section{Introduction}

One of the unique features of the human species is the ability of its individuals both to imagine and articulate future possibilities. The age-old dream of space travel, for example, is now a reality. The natural extension of this dream has it that where humans can travel and explore, they might also settle and so the idea of space settlement has never been far behind that of travel. Living somewhere else but Earth has been a theme in the space literature as far back as the writings of Tsiolkovskii and, if the space program can be said to have a purpose beyond that of exploration, this purpose is occasionally articulated in terms of settlement, such as in 1986 when the US National Commission on Space stated its conclusion that the proper long-range ambition of the US civilian space program should be to establish free societies on new worlds "from the highlands of the Moon, to the plains of Mars" [1].

It is not surprising that there are no locales in space yet discovered which are habitable. Humans live within, and are part of, the Earth's biosphere which can be viewed as a biogeochemical life-support system englobing the planet and extending from the top of the atmosphere to substantial depths within the crust. There are no other 'Earths' in the Solar System which duplicate these condi- tions - and they would already be inhabited by some sort of life if there were. Thus, the challenge of space settlement involves the creation of artificial and autonomous biospheres which can resist or adapt to local barren conditions. Here we have the reason why settlement lags at least four decades behind travel and still remains to happen: the science of life-support systems is much more complicated and poorly understood than rocket science.

Nevertheless, space remains an energy- and materialrich frontier [2] and there have been a number of technical assessments of space as an arena for human endeavour since the dawning of the Space Age. The most well known of these are the proposals of O'Neill and followers in the 1970s which involve the fabrication (from lunar or asteroidal materials) of large orbiting habitats, spun to create artificial gravity and landscaped on the interior, providing a quasi-natural environment $[3,4]$. Originally, it was envisaged that these habitats would house workers building solar power satellites for Earth. But if the initial operations could be made to pay, it was natural to predict the more self-sufficient of these orbiting city states adopting a more independent course and moving away from the environs of Earth altogether. Humanity would have evolved into a spacefaring civilisation.

While generating considerable interest at the time, the fashion for O'Neill's ideas has declined to be replaced by 
an enthusiasm for Mars. Much of the technical evaluation of the prospects for exploring and settling Mars was organised under the umbrella of the Case for Mars conferences which, until recently, were held every three years since the first conference in 1981 [5-7]. Over the past two decades, a substantial and diverse number of people have contributed to sustaining and elaborating the concept and the modern work continues [8-10]. A successor paradigm is arising too which is specifically to do with the fact that Mars is a planet. It may be that on Mars we can re-create the sort of autonomous and regenerative life-support system that sustains us on Earth a planetary biosphere.

This concept of engineering habitable worlds out of barren ones is known as terraforming. The concept first appeared in Olaf Stapledon's fictional tour de force Last and First Men in 1930 [11], and was given its name by Jack Williamson in a short story Collision Orbit in 1942 [12]. Sagan, in 1961, was the first scientist to speculate about terraforming in the pages of a technical journal [13], and by 1976 NASA had published the proceedings of a workshop examining the feasibility of terraforming Mars [14]. During the 1990s, another surge of interest in terraforming Mars not only made progress in technical areas but also provoked wider questions about the enterprise, and space settlement in general $[15,16]$. The mining of asteroids when there are so many, or quarries on the Moon when it is already so bleak, or settlements in empty space provoke few moral reflections; but the biological transformation of an entire world makes people sit up and think - to confront similar questions to those we are asking of our relationship with the Earth. We are increasingly seeing the need for an ethical relationship with our planet: should we be thinking similarly with respect to the extraterrestrial environment?

\section{Environmental ethics and space}

Ethics is that branch of philosophy which deals with issues of good versus evil behaviour and hence defines acts which are morally permissible or obliged. Only within the last 100 years, however, has ethics begun to expand its concern from human interactions to encompass the moral relationship human beings should have with nature. The need for such an environmental ethic seems especially pressing when issues of animal rights are raised and when environmental crises, often precipitated by human activity, occur. At the start of the new century, environmental ethics is now a thriving discipline [17], with a serious and rational voice that is a welcome addition to the more emotive character of 'green' politics.

However, the perceived problem with environmental ethics in its current form is that it is geocentric in context. The Earth is effectively viewed as a sealed box, transparent to incoming sunlight and outgoing heat. Space simply lies beyond moral concern: beyond issues of right and wrong. Perhaps, given our record of developing environmental ethics in response to crisis, this is not surprising. The only environmental problem that currently looms from our minimal utilisation of space is the escalating problem of debris in Earth's orbit. But this is viewed merely as a threat to personnel and hardware safety and does not bring to the fore any more fundamental questions of the rights and wrongs of space utilisation itself.

An early attempt to remedy this conceptual deficiency occurred at a multidisciplinary conference 'Environmental Ethics and the Solar System', held at the University of Georgia in 1985. The proceedings, with the varying views of space technologists, astronomers, philosophers, ecologists, lawyers and theologians were later published [18], but represented purely initial explorations in the subject rather than a consensus prescription for the future. This would be premature, but the approach is correct - since a cosmocentric environmental ethic aims to be proactive rather than reactive, it must proceed by thought experiment. Sometimes, it is the grandest thought experiments than can uncover the most fundamental issues and so scientists speculating on the possibility of terraforming Mars have been particularly interested in its moral dimensions. If we can visit Mars, live there, and ultimately terraform the planet, would it be right to do so? Is Mars just potential real estate or does it have an inherent right to eternal preservation? And what rights would be due to any Martian life, surely in microbial form, should any be discovered? Should bacteria have rights on Mars?

Haynes was the first to turn his attention to these questions and to commend the concept of terraforming Mars as an ideal arena within which to develop future, cosmocentric, environmental ethics [19]. McKay's comparative survey of environmental ethics led him to choose three competing theories which he projected beyond their geocentric remit to illuminate Mars [20]. His prescription was that terraforming Mars would be permissible, provided that the planet is sterile. Should Mars have life he proposed, "humans ... should undertake the technological activity that will enhance the survival of any indigenous Martian biota and promote global changes on Mars that will allow for maximising the richness and diversity of these Martian life forms". However, what McKay's paper also illustrated was the contrast between alternate theories. He could quite easily have come to a different conclusion. Turner's wideranging analysis, which borrows heavily from the fields of restoration ecology and aesthetics, argues powerfully in favour of the moral worth of terraforming:

In this work, we may become the seed-vectors and pollinators of the universe, carrying life beyond the fragile eggshell of the planet, so exposed to sterilisation by a stray asteroid strike or an extra-large comet... 


\begin{tabular}{|c|c|c|}
\hline Ethical theory & Central moral principle & Basis of intrinsic value \\
\hline Anthropocentrism & Categorical imperative & Rational and moral capacity \\
\hline Zoocentrism & Principle of utility & Individual consciousness \\
\hline Ecocentrism & Principle of respect for life & All life \\
\hline Preservationism & Principle of the sanctity of existence & Uniqueness or "formed integrity" \\
\hline
\end{tabular}

We should do this not only because it is a noble thing to do in itself, but because we will not ever know with any confidence how our own planetary ecosystem works until we ourselves have created one on another planet [21].

Few prescriptions however are articulated with Turner's poetic confidence. MacNiven refrained from any prescription at all from his study of the ethics of terraforming Mars and was content to flesh out the rival theories that might be applied [22].

Four such rival theories, which are broadly representative of the spectrum of ethical thought, are summarised in Table 1. Each theory adopts a central moral principle from which to assert its ethical perspective and assumes a basis for intrinsic value, hence defining that set of moral patients due to direct moral consideration. Intrinsic value is a meta-ethical concept that is defined as that value of an object that is independent of a valuer. The possessor of intrinsic value is a 'rights-holder', entitled to justice and respect. Instrumental value is that value that requires a valuer. An object of purely instrumental value has no rights and can rightly be used to serve as a means to accomplish a moral goal.

\subsection{Anthropocentrism}

The system of ethics under which we now live - the 'default' system, we might call it - is anthropocentrism (sometimes called homocentrism) which has ancient roots in both secular and religious philosophies. Only human beings have rights within anthropocentrism, which holds that the basis of intrinsic value is the individual's capacity to think rationally and act morally. Moral agents are hence moral patients. If developed along Kantian lines, anthropocentrism would uphold a Principle of Respect for Persons: that people should be treated as ends-inthemselves and not as a means to an end. People have a right to exist, are entitled to their dignity and freedom from injustice.

The rest of nature though is seen as amoral and hence is assigned no moral standing. Nature is valuable in that it contributes to human welfare, but animals, plants, microbes, the ecosystems of which they are a part, and the inorganic stuff of planet Earth have no rights other than those that humans choose to give them on instru- mental grounds. With nature regarded in this way purely as a resource, one might regard anthropocentrism as not being an environmental ethic at all, but merely as a selfserving excuse for exploitation. This perhaps reflects history. However historical experience has been teaching us, in increasing measure, the value of nature for the present and future well-being of mankind - both materially and spiritually. The Earth and its ecosystems are both the human life-support system and the arena in which our minds take shape. The environment is an anthropocentric issue. Anthropocentric morality would therefore hold that, although our obligation toward nature is indirect, it is nonetheless real. Humans should therefore balance exploitation with preservation to provide for the material needs of future generations, and should refrain from gratuitous cruelty and destruction that only serves to corrode the human spirit. We must cultivate an enlightened self-interest and take on the role of 'wise stewards' of planet Earth $[23,24]$.

It is clear that anthropocentrism poses no fundamental moral objection to terraforming Mars, or to any lesser colonisation activities in space. If they can be shown to be to the good of humanity, then such objectives are good in themselves and may, and perhaps should, be put into practice. Many arguments have been advanced as to the benefits that the opening of the space frontier would have for humankind and one does not have to look far on Mars to find them $[25,26]$.

But anthropocentrism does not automatically sanction terraforming. If the relative instumental value of Mars is greater with the planet left untouched, then it should be so for as long as such a judgement remains true. One can think of several reasons why this might happen. Mars must surely surrender its scientific secrets first before it is exploited and if there is life there, then it must be studied in its natural environment. If the expense of space settlement could be shown to incur a net detriment to human well-being, then this would also rule out the enterprise. These objections, however, represent human interests and not the assignation of any intrinsic worth to the extraterrestrial environment. They would thus be subject to re-evaluation in the light of changing circumstances. For the anthropocentrist, it is humanity that counts: if Mars counts more to us as a second home than as a barren desert, then living there, and terraforming the planet, would be a moral cause. 


\subsection{Zoocentrism}

An expansion of moral rights beyond the purely human sphere has been urged for many years by animal rights and vegetarian groups [27]. Many of these arguments can be contained within an ethical system variously called zoocentrism, zootic individualism or extensionism. If regarded from the standpoint of the Principle of Utility - that morality involves maximising happiness and minimising suffering - then individual consciousness becomes the basis of intrinsic value. While the debate over the nature of animal consciousness continues, few would deny that 'higher' animals at least have feelings and are capable of pleasure and pain. Animals are subjects of a 'biographical life' [28].

A zoocentrist would thus assign intrinsic value to animals that are considered sentient (a somewhat ill-defined value set) and would claim the same moral standing for them as for humans. The adoption of zoocentrism as our environmental ethic would require us to treat animals more like people. Exploiting animals for food, medicine, science or degrading entertainment would be immoral and we would have to strive to uphold animal as well as purely human welfare.

Zoocentrism assigns no intrinsic value to 'lower' organisms, and inanimate objects. These remain of instrumental value to animal-kind. Looking out into space, we have so far seen nothing of intrinsic value to the zoocentrist. If colonising space and terraforming Mars would be of benefit to conscious existence, then - to the zoocentrist as well as the anthopocentrist - it would be a right and a proper thing to do.

\subsection{Ecocentrism}

Ecocentrism (also known as biocentrism) is claimed by its proponents to be the first true environmental ethic since it is based on holistic principles. To the ecocentrist, all life is sacred and has the right to exist and flourish. The living world itself has intrinsic value: not just at the level of individual organisms, but also the ecosystems of which they are a part $[29,30]$. Humans are not regarded as a superior species [31], but as just one part of this greater whole - 'plain biotic citizens' is a term often used - with no right to assert themselves over and above the will of nature. Moral behaviour within this system entails serving the welfare of life as a whole: following a Principle of Respect for Life, often defined as "preserving the integrity, stability and beauty of the biotic community" [29]. Since humans have no privileged place within this community, ecocentrists urge that we dismantle our energy and resource-intensive civilisation, reduce our population, and adopt a simpler lifestyle in harmony with nature.

Since ecocentrism subordinates the rights of the individual to those of an holistic abstraction, it has been criticised as a misanthropic and totalitarian ideology [32]. This is not without some justification, as much of the progress in ethics over the past few centuries has involved the extension of individual rights - many of which ecocentrism would require us to abandon. However, much of this criticism only fully applies to the more extreme versions of ecocentrism. Half the human population, big though it is, cannot be allowed to starve, however much this might suit the abstract purposes of the biosphere. This really would be immoral. The original 'Land Ethic' of Leopold has thus been interpreted by some to mean something more akin to: the survival needs of humans outweigh the survival needs of non-humans, but the survival needs of non-humans outweigh the nonsurvival needs of humans [33]. An ethic such as this stands not too far removed from some 'enlightened selfinterest' versions of anthropocentrism.

Vast and fuzzy though the expanded set of rights holders within ecocentrism is, the system still does not assign intrinsic value to inanimate objects. Life is the basis of value: planets and the rocks they are made of provide an instrumental stage within which life can play out its destiny. Thus, despite ecocentrism's hostility towards human technology, space settlement and terraforming are not necessarily immoral within an ideology such as this. In fact it is quite the contrary: maximising the diversity of life is one of the principles of ecocentrism. Undoubtedly however, extraterrestrial life, of whatever kind, would also be assigned intrinsic value from the ecocentric perspective [20]. We would have to further the interests of whatever life forms we encounter in space. Bacteria at home on Mars would have moral priority over humans. Their scientific usefulness to us would be irrelevant as a criterion for their preservation. They would be entitled to this by right. To the ecocentrist, terraforming Mars is only moral if it is truly a barren world.

\subsection{Cosmic preservationism}

It is clear therefore that geocentric theories of environmental ethics, when projected into space, do not categorise space settlement and terraforming as wrong. This has caused some philosophers to react with concern. Those who believe that nature should be respected as it is, irrespective of context, feel that whatever the intrinsic values of terrestrial life and its subsets, these are not values that can be imposed on the extraterrestrial environment. The cosmos has its own values, they claim, and its mere existence gives it not only the right to exist, but the right to be preserved from any human intent. Such a moral principle we might call the Principle of the Sanctity of Existence, with uniqueness as its basis of intrinsic value. Moral behaviour under such a system would involve non-violation of the extraterrestrial environment and the preservation of its existing state. 
Uniqueness is a slippery concept and could conceivably be applied to all existing objects, from whiffs of interstellar gas to galaxies. The fuzziness of value distributed in this way seems to undermine the very point of moral philosophy since its only imperatives are to exist and not to prevent other things from existing. Rolston, an exponent of Preservationism, has therefore defined the uniqueness set as containing any object - alive or not - of "formed integrity", or "worthy of a proper name", generated by the "spontaneous construction" that arises from the playing out of the laws of nature. His presciption is that, "humans ought to preserve projects of formed integrity wherever found" [34]. Mars, and all its features large and small - would be entitled protection within Rolston's ethic. Rocks would have rights on Mars.

To those who are bemused by this idea, Marshall (another cosmic preservationist) ripostes with the belief that intrinsic value is not imposed by human beings, but merely involve human recognition of value [35]. To him, rocks also have a viewpoint that commands respect: existing in, "a blissful state of satori only afforded to non-living entities". With respect to Mars especially, Marshall advocates strict enforcement policies to preserve the planet in its existing, or 'natural' state.

It is curious to note that, at the end of their papers, both these philosophers appear to make a partial retreat from their prescriptions. Perhaps these are fall-back positions in the expectation of strict preservationism never being accepted. Both urge that if space settlement ever proceeds then a representative portion of the extraterrestrial environment should be preserved, but cast doubts on whether this is realistically possible. If life were to be found on Mars, then Marshall augments his position with ecocentrism and recommends permanently quarantining the planet. Ideally, cosmic preservationists would like terrestrial life to stay at home, to observe and empathise with the universe, not to invade it.

\section{Reflections and conclusions}

Would terraforming Mars, and space settlement generally, lead to the betterment of humanity? The answer is a likely yes, given the caveat mentioned above, that the process is not to the detriment of the population that remains resident on the Earth. Would these activities be to the betterment of life as a whole? Here, we can reply with a certain yes. Life is a phenomenon at least 3.8 billion years old with no intrinsic expiry date. Yet our Solar System is middle aged and the Sun's fiery senescence will ensure that the Earth will not remain habitable indefinitely. Total extinction of terrestrial life can thus only ultimately be avoided by vacating our planet for a more benevolent locale elsewhere in the cosmos.

Would terraforming lead to the betterment of Mars itself? It is this question that is at the heart of the debate.
Yet if Mars is a barren planet, does this question even fall within the scope of morality? Preservationists would have it so, and others whose philosophy is less clear cut. It is common at conference debates to hear people, whose earth-bound ethic is clearly not preservationist, articulating a preservationist line with regard to the cosmos. While choosing one's paradigm according to context and personal taste may be problematic within science, it is not necessarily so in philosophy. You could reject realism (belief in a universal moral standard) and argue instead for relativism or pluralism and apply different ethical theories to different situations; and even if you remained a realist, you have the initial choice of a wide variety of belief systems. But does not this freedom in itself cast doubt on the validity of the values claimed for nonhuman, and especially non-living, objects? It does seem that, whatever the intrinsic value in nature beyond the confines of our human bodies, since morals are there to constrain our behaviour, values still seem to boil down to what we think and how effective we are at influencing the behaviour of others.

Does a barren Mars really have intrinsic worth, or are the claims to this effect actually human values in disguise? A striking feature of the ethical spectrum displayed in Table 1 is that the further one looks down the Table, away from the position of anthropocentrism, the greater is the moral constraint on human freedom of action within the environment and the greater are our duties towards it. Since morality is there to regulate our behaviour alone, these philosophies often resort to justifying their positions with misanthropic arguments: gloomy critiques of humanity that emphasise our capacity for evil. To the zoocentrist, humans are unnecessarily cruel to our fellow creatures; to the ecocentrist, we are seen on the one hand as nothing special, and on the other, uniquely arrogant and destructive. To the cosmic preservationist, the idea of letting loose such a wicked and cancerous species on the Universe at large is nothing short of an abomination. Misanthropy thus also increases in measure down Table 1, and since misanthropy is evidently held as a valuable belief by some, it is itself a human value of sorts.

The same applies to sentimentality, nicely defined recently as, "the elevation of feelings, image, spontaneity over reason, reality and restraint" [36]. A prime example of this is the ecocentrist notion of ecological harmony: that there exists an ideal balance in nature that is perfect, unchanging, and which nurtures and sustains. Yet this is little more than a cosy illusion, based on out of date ecology. Nature is not static and unchanging and is better regarded as a continuous state of flux dominated by chaos and disharmony [21,37]. The history of our planet tells us in no uncertain terms that any harmony that may appear as an epiphenomenon of this state of affairs is transient. Innovation, evolution and extinction - all processes of irreversible change - represent the 
true natural order of life and, on differing timescales, they are a partial reality for inanimate existence too. And while it is reasonable to propose that animals with advanced nervous systems might have feelings, and therefore a point of view, surely it is a gross sentimentality to propose such a thing for rocks. After all, a sentimental terraforming enthusiast might propose that, far from the rocks on Mars existing in a state of 'blissful satori' (as a preservationist would have it) they might instead be 'crying out for life'. Both arguments are unedifying. Rocks don't think, don't act and don't care. They cannot have values of their own.

Consider two scenarios where life is brought to a barren Mars and the differing reactions environmental philosophers might have to each. For the purposes of the first, let us propose that we discover that microbial life from Earth has already reached Mars, having arrived there at some time in the distant past by some sort of panspermia process. The possibility that bacteria could make such a journey across space was first proposed by Arrhenius a century ago [38], and has been revived in a different guise recently when it was realised that planets exchange pieces of themselves following impacts energetic enough to propel debris into space. Bacteria living in the middle of an ejecta fragment might be sufficiently shielded from heat shock and radiation to survive many years in transit and the final trauma of touchdown onto the new world [39]. Would this discovery be morally criticised by preservationists? Might they consider that founding colony of microbes to have been violators of Mars? Might they regard its descendants, the extant population, to be a form of immoral pollution? Of course not. Bacteria cannot be praised or blamed for being in the right place or the wrong place at the right time. The discovery would be regarded as a particularly noteworthy event in the history of life, but one undeserving of moral censure. Even the most hard-line preservationists would concede the contaminating event as a natural event. Arriving on a meteorite, those pioneer microbes no more polluted Mars than the first living cell polluted the Earth.

In our second scenario, however, it is humans who take life to Mars, who alter the climate of the planet so it can support a thriving ecosystem. We terraform Mars. Now there is an obvious ethical dimension: would it be right or wrong for us to do this? Perhaps in the light of scenario one though, the question can be rephrased. If the unconscious diversification of life is not a moral issue from the standpoint of Mars, why is it that intentional diversification be subject to moral scrutiny? The reason is that only humans are subject to moral praise or blame. It is our own values that are at issue, not fictional ones ascribed to unconscious or non-living entities. They are the only values that we can know to be real and the only ones that can motivate both action and restraint.

It is thus the conscious enactment of change that preservationists most object to, in the same manner that ecocentrists object to it on Earth. But is there anything fundamentally unnatural or wicked inherent in this ability? No. While we are right to regard the Universe, with all its projects, from the vast to the microscopic, with wonder and a degree of humility, the Universe does seem to be a reasonable place. It seems to be showing us that it is comprehensible, if not all comprehended. It is subject to cause and effect, to free will. Reason therefore, as suggested by Plato and Kant, has a transcendent and autonomous nature. It can be projected as well as contained within the self. Its province is the Universe at large. Reason can enact intentional change. It can legitimately stand against what is, for ideals of what ought to be. Human consciousness, culture, creativity - and the technological artefacts produced thereby - are thus not unnatural. They have arisen from the same physics that gave birth to the cosmos and the same process of biological evolution that followed the genesis of the first living cell. They are as natural as sex, photosynthesis, aerobic respiration, and a host of other biological processes, all of which came into being some considerable time after life's origin and all of which changed the Earth drastically and forever.

Would Mars be a better place transformed into a living world? Preservationism would say no, but its movement from what is descriptively true of Mars to a prescriptive claim is arbitrary and unconvincing. The argument amounts to saying that humans actually have the lowest degree of intrinsic worth of any class of formed object. Rocks are free to rust and crumble over the aeons, asteroids and meteorites free to batter the Martian surface, and microbes free to hitch a ride if they can survive the trip and there to evolve in to new forms that are Martian. Only humans should be constrained from fulfilling their evolutionary potential according to this philosophy. Yet if spacefaring is a legitimate activity for microbes, why should it not be so for humans? The allied ideologies of misanthropy and sentimentality cannot provide a satisfactory answer.

There is no fundamental moral objection to bringing life to Mars as opposed to it originating there, or arriving there by accident. If life begins on Mars during the planet's middle age, as opposed to its youth, then this is more an issue of timing than of morality. Life might change Mars but it will not detract from the planet's uniqueness. This is not to say that there are no moral issues inherent in space settlement - there will still be right and wrong ways to go about it - but we will have to appeal to our own values in order to resolve them.

\section{References}

[1] National Commission on Space. Pioneering the space frontier. New York: Bantam Books, 1986. 
[2] Lewis J. et al., editors. Resources of near Earth space. Tucson: University of Arizona Press, 1993.

[3] O'Neill GK. The high frontier. London: Corgi Books, 1978.

[4] Johnson RD, Holbrow C. editor. Space settlements - A design study. NASA SP-413, 1977.

[5] Boston PJ. editor. The case for Mars. AAS Science and Technology Series, vol. 57. 1984.

[6] McKay CP. editor. The case for Mars II. AAS Science and Technology Series, vol. 62. 1985.

[7] Stoker CR. editor. The case for Mars III. AAS Science and Technology Series, vol. 74-75. 1989.

[8] Ishikawa Y, Ohkita T, Amemiya Y. Mars habitation 2057: concept design of a Mars settlement in the year 2057. JBIS 1990;43: 505-512.

[9] Zubrin RM, Wagner R. The case for Mars: the plan to settle the red planet and why we must. New York: Free Press, 1996.

[10] Zubrin RM. editor. From imagination to reality: Mars exploration studies of the journal of the British interplanetary society. AAS Science and Technology Series, vol. 91-92, 1997.

[11] Stapledon O. Last and First Men. London: Methuen, 1930.

[12] Stewart W. Collision orbit. Astounding Science Fiction 1942;XXIX(5):80-117.

[13] Sagan C. The planet Venus. Science 1961;133:849-58.

[14] Averner MM, MacElroy RD. On the habitability of Mars: an approach to planetary ecosynthesis. NASA SP-414, 1976.

[15] McKay CP, Toon OB, Kasting JF. Making Mars habitable. Nature 1991;352:489-96.

[16] Fogg MJ. Terraforming: engineering planetary environments. Warrendale, PA: SAE International, 1995.

[17] Armstrong SJ, Botzler RG. Environmental ethics: divergence and convergence. New York: McGraw-Hill, 1993.

[18] Hargrove EC. editor. Beyond spaceship Earth: environmental ethics and the solar system. San Francisco, CA: Sierra Club Books, 1986.

[19] Haynes RH. Ecce ecopoiesis: Playing God on Mars. In: MacNiven D, editor. Moral expertise. New York: Routledge, 1990. p. 161-83.

[20] McKay CP. Does Mars have rights? An approach to the environmental ethics of planetary engineering. In: MacNiven D, editor. Moral expertise. New York: Routledge, 1990. p. 184-97.
[21] Turner F. The invented landscape. In: Baldwin AD et al., editors. Beyond preservation: restoring and inventing landscapes. Minneapolis: University of Minnesota Press, 1994. p. 35-66.

[22] MacNiven D. Environmental ethics and planetary engineering. Journal of the British Inteplanetary Society 1995;48:441-3.

[23] Murdy WH. Anthropocentrism: a modern version. Science 1975;187:1168-72.

[24] Gould SJ. The golden rule - a proper scale for our environmental crisis. Natural History, September 24-30, 1990.

[25] Zubrin RM. The significance of the Martian frontier. Ad Astra 1994;6(5):29-37.

[26] Turner F. Terraforming and the coming charm industries. Adv. Space Res. 1988;22(3):433-9.

[27] Regan T. The case for animal rights. Berkeley, CA: University of California Press, 1983.

[28] Rachels J. Created from animals: the moral implications of Darwinism. Oxford: Oxford University Press, 1990.

[29] Leopold A. The land ethic. A sand county almanac. Oxford: Oxford University Press, 1977. pp. 201-26.

[30] Callicott JB. The conceptual foundations of the land ethic. Companion to a sand county almanac. University of Wisconsin Press, 1987. pp. 186-217.

[31] Ehrenfeld DW. The arrogance of humanism. Oxford: Oxford University Press, 1978.

[32] Kheel M. The liberation of nature: a circular affair. Environmental Ethics 1985;7:241-56.

[33] Heffernan JD. The land ethic: a critical appraisal. Environmental Ethics 1982;4:235-47.

[34] Rolston III H. The preservation of natural value in the solar system. In: Hargrove EC, editor. Beyond spaceship earth: environmental ethics and the solar system. San Francisco, CA: Sierra Club Books, 1986. p. 140-82.

[35] Marshall A. Ethics and the extraterrestrial environment. Journal of Applied Philosophy 1993;10(2):227-36.

[36] O'Hear A. Diana, queen of hearts: sentimentality personified and canonised. In: Anderson D, Mullen P, editors. Faking it: the sentimentalisation of modern society: The Social Affairs Unit, 1998.

[37] Worcester D. The ecology of order and chaos. Environmental Review 1990;14(1-2):1-18.

[38] Arrhenius S. Worlds in the making. London: Harpers, 1908.

[39] Sleep M, Zahnle K. Journal of Geophysical Research 1998; 103(E12):28529-44. 